\title{
Influence of patient position and implant material on the stress distribution in an artificial intervertebral disc of the lumbar vertebrae
}

\author{
Robert Karpiński ${ }^{1, *}$, Lukasz Jaworski ${ }^{2}$, Mirosław $\mathrm{Szala}^{3}$, and Monika Mańko ${ }^{4}$ \\ ${ }^{1}$ Lublin University of Technology, Faculty of Mechanical Engineering, Department of Machine Design and Mechatronics, \\ Nadbystrzycka 36, 20-618, Lublin, Poland \\ ${ }^{2}$ Poznan University of Technology, Faculty of Mechanical Engineering and Management, Piotrowo 3, 60-965, Poznań, Poland \\ ${ }^{3}$ Lublin University of Technology, Faculty of Mechanical Engineering, Department of Materials Engineering, Nadbystrzycka 36, \\ 20-618 Lublin, Poland \\ ${ }^{4}$ Lublin University of Technology, Faculty of Electrical Engineering and Computer Science, Nadbystrzycka 38A, 20-618, Lublin, Poland
}

\begin{abstract}
The aim of this paper was to determine the effect of using cobalt and titanium-based alloys as implant materials for the lumbar vertebrae with an artificial intervertebral disc on the stress distribution. The lumbar vertebrae were chosen for the study because they carry considerably higher loads, especially while standing or sitting. Finite element method (FEM) simulations were conducted for three standard loads reflecting three patient's positions: recumbent, standing and sitting. The FEM analysis was performed using the SolidWorks Simulation module. Artificial units containing a pair of vertebrae with a prosthesis between them were designed by the Solid Edge software, based on micro-computed tomography CT scans of the patient's spine. The implant model was designed with its shape based on the geometry of surrounding vertebrae, consisting of an upper pad, a bottom pad and an insert (intervertebral disc). Two implant material configurations were studied. One involved the use of titanium alloy for the upper and bottom pads, while in the other, these pads were made of cobalt alloy. In both cases, a polyethylene insert was used. The FEM results demonstrate that both material configurations meet the requirements for prosthesis design. In both material configurations, the maximum stresses in each prosthesis element are almost twice higher in a sitting posture than in a recumbent position.
\end{abstract}

\section{Introduction}

Spinal diseases pose a serious problem both from a point of view of diagnosis and treatment as well as biomechanics. The mechanisms of development of an abnormal posture of the human body are not fully understood yet, which makes rehabilitation and treatment difficult.

The range of segmental motion of the spine is a standard clinical assessment of motor organs. It is reported in literature [1-4] that computer-aided methods (CAD) are necessary in biomechanics, so the applications of the finite element method (FEM) are constantly developed. Modern computer technology enables the development of increasingly advanced numerical models not only of the human spine [1], but also dentate prostheses [2], knee or hip joints [3,5], dentinal microtubules [4], which - combined with engineering and medical knowledge - provides an excellent basis for conducting biomedical research and analyses that ensure optimal choice of treatment or rehabilitation methods for the spine. Nowadays it is possible to simulate models of entire biomechanical systems and individual elements tailored to the needs of a particular patient. This is in agreement with the current trend for implant personalisation in biomedical engineering.
Micro-computed tomography (CT) is useful in solving biomedical problems [5-8]. Based on images obtained from the CT scans of the human spine, it is possible to perform said personalised treatment in the area of intervertebral disc replacement. In such cases, one of the first stages of treatment is to design an artificial intervertebral disc. However, various biomaterials are available that could be considered for implant applications [1, 3, 9-13], and FEM simulations are helpful in proper material selection.

The aim of this study is to determine the effect of using cobalt and titanium-based alloys as implant materials for lumbar vertebrae with a polyethylene intervertebral disc on stress distribution. FEM simulations are conducted for three standard loads reflecting the following positions of the patient: recumbent, standing and sitting.

\section{Structure of the spine}

The spine provides support for the upper body. Depending on the location, the vertebrae are divided into: 7 cervical vertebrae, 12 thoracic vertebrae, 5 lumbar vertebrae, 5 sacral vertebrae and 4 or 5 coccygeal vertebrae [14]. The cervical, thoracic and lumbar vertebrae are the movable presacral part of the spine, and are called true vertebrae.

\footnotetext{
Corresponding author: r.karpinski@pollub.pl
} 
The intervertebral disc is a connector between the true vertebrae. There are 23 intervertebral discs in the spine which connect the surfaces of two adjacent vertebral bodies $[15,16]$. The adjacent vertebrae are mutually stabilized by a strong ligament apparatus. Two connected vertebrae with an intervertebral disc are shown in Fig. 1.

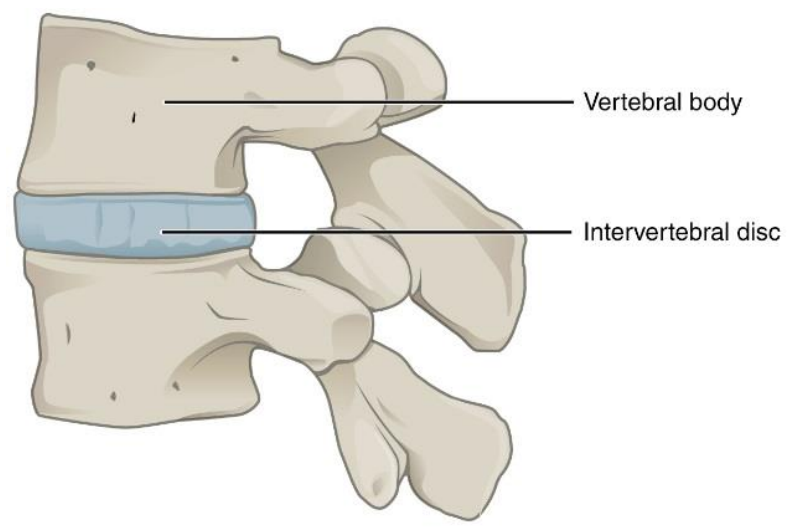

Fig. 1. Connection of two vertebrae, lateral view [17].

The lumbar vertebrae is characterised by its size and mass [18]. The lumbar spine as seen from above is shown in Fig. 2.

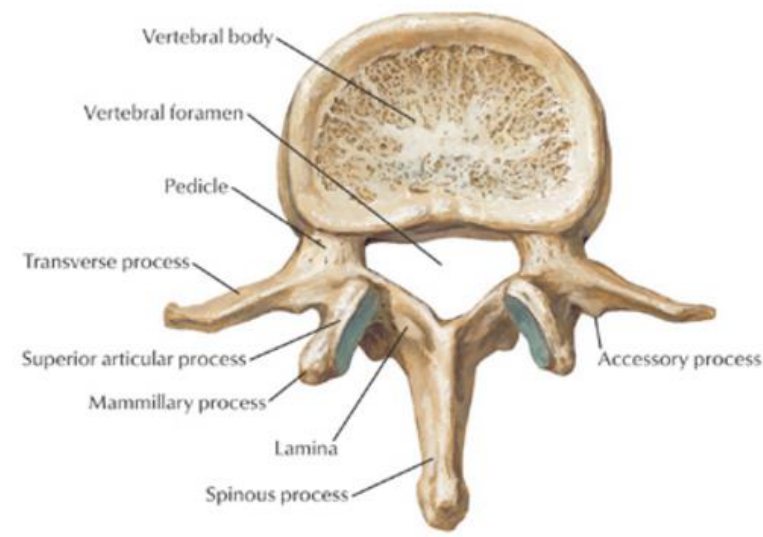

Fig. 2. Lumbar spine as seen from above [14].

Typical discs are made up of boundary plates, fibrous rings and atherosclerotic nuclei. The fibrous ring consists of a dozen layers of variable material characteristics and encapsulates an incompressible gelatinous atherosclerotic nucleus. The stiffness of the fibrous ring layers decreases with the distance to the canter of disc, the outer layers have the highest rigidity and are the least susceptible to deformation [19].

The discs on each level have a similar shape but vary in dimensions. The height and width of the lumbar discs are almost twice as high as those of the discs in the neck. As is the case with the articular cartilage, the performance of the intervertebral disc depends on the degree of saturation by water and the degree of degeneration. With age, they flatten and lose some elasticity. The main tasks of the intervertebral discs are to ensure the stability of the spine, damp vibration of the vertebrae and act as a link enabling the adjacent vertebrae to move [20, 21].

\section{Materials and methods}

For our study, we chose lumbar vertebrae due to the fact that they carry considerably larger loads, especially while standing or sitting. The patient's vertebrae were measured using CT (micro-computed tomography), and selected results are given in Fig. 3. Artificial units containing a pair of vertebrae with a prosthesis between them were modelled with Solid Edge ST8 (CAD software) based on CT scans of the patient's spine. The basic shape of the bottom pad and polyethylene insert were designed. The insert's dimensions had to exactly match the size of the bottom pad, as these two elements are closely intertwined [5]. When assembled, these elements form an endoprosthesis. The original implant model had a shape based on the geometry of the surrounding vertebrae and consisted of an upper pad, a bottom pad and an insert (intervertebral disc), shown in Fig. 4.

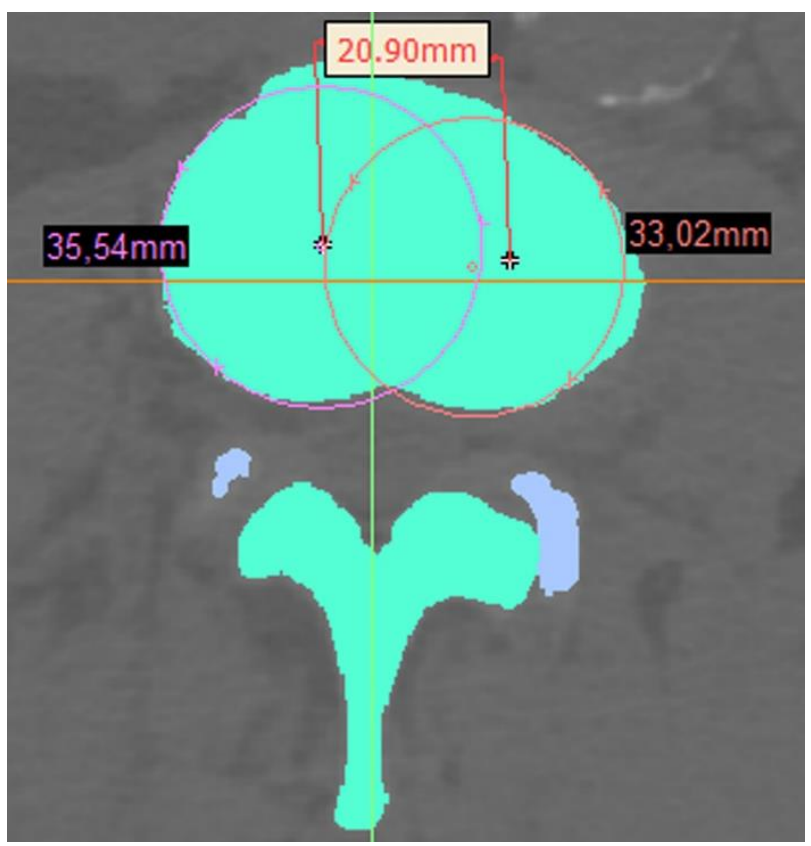

Fig. 3. Measurements performed with CT scans of the patient.

For the purpose of the study, three construction materials were used: ultra-high-molecular-weight polyethylene for the insert, titanium alloy Ti-6Al-4V and cobalt alloy Co-Cr-Mo for the bottom and upper pads of the prosthesis. The mechanical properties of these materials are given in Table 1.

Table 1. Mechanical properties of tested materials.

\begin{tabular}{|c|c|c|c|c|}
\hline Material & Element & $\begin{array}{c}\text { Young's } \\
\text { modulus } \\
{[\mathbf{M P a}]}\end{array}$ & $\begin{array}{c}\text { Poisson's } \\
\text { ratio [-] }\end{array}$ & $\begin{array}{c}\text { Density } \\
{\left[\mathbf{g} / \mathbf{c m}^{3}\right]}\end{array}$ \\
\hline $\begin{array}{c}\text { Titanium } \\
\text { alloy } \\
\text { Ti-6Al-4V }\end{array}$ & $\begin{array}{c}\text { Upper, } \\
\text { bottom } \\
\text { pad }\end{array}$ & $1.05 \cdot 10^{5}$ & 0.31 & 4.43 \\
\hline $\begin{array}{c}\text { Ultra-high- } \\
\text { molecular- } \\
\text { weight } \\
\text { polyethylene }\end{array}$ & Insert & 1070 & 0.41 & 0.95 \\
\hline $\begin{array}{c}\text { Cobalt alloy } \\
\text { Co-Cr-Mo }\end{array}$ & $\begin{array}{c}\text { Upper, } \\
\text { bottom } \\
\text { pad }\end{array}$ & $2.2 \cdot 10^{5}$ & 0.22 & 8.4 \\
\hline
\end{tabular}




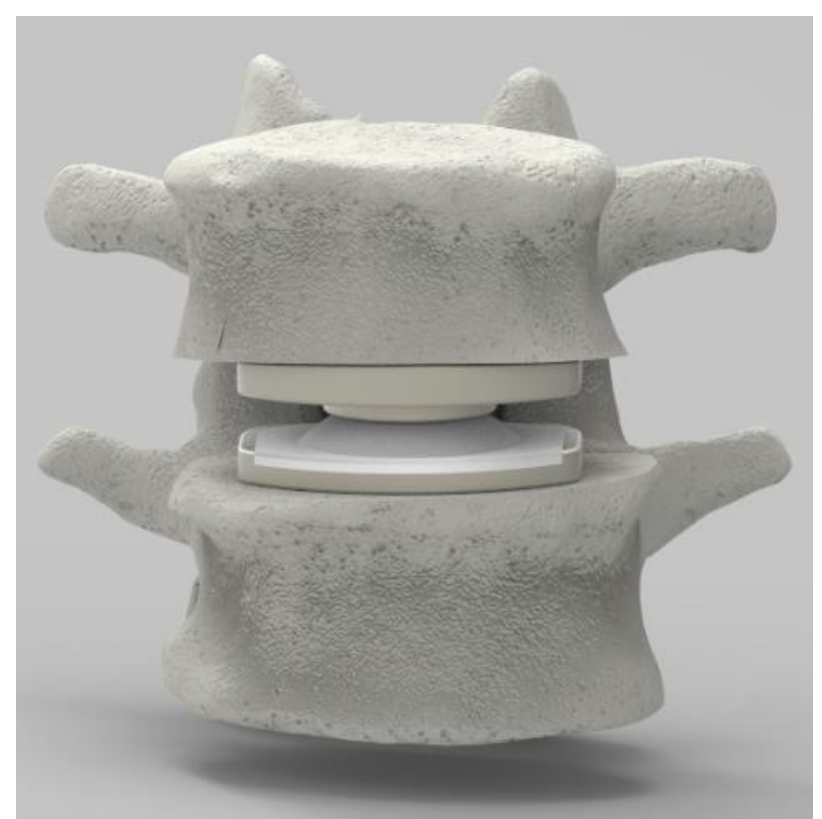

Fig. 4. Original model of artificial intervertebral disc with dimensions corresponding to CT result presented in Fig. 3.

The FEM modelling was performed using the SolidWorks Simulation module. The model was fixed rigidly on the underside of the bottom plate, imitating the connection between the fourth lumbar vertebra. By analogy, the loads were applied to the surface of the upper pad where the implant is attached to the third vertebra. Two configurations of the prosthesis materials were investigated: (I) upper and bottom pads made of titanium alloy, and (II) upper and bottom pads made of cobalt alloy, both configurations with a polyethylene insert.

The FEM analysis of the units containing a pair of vertebrae with a prosthesis between them was conducted under various load conditions, depending on the body position. The value of load was intended to represent the force acting on the intervertebral disc of a $100-\mathrm{kg}$ body weight (BW) patient. We studied different human body positions: recumbent, standing and sitting, with the BW percentage being $75 \%, 100 \%$ and $140 \%$, respectively [22].

Constraints and loads are shown in Fig. 5. The simulation module generated a triangular mesh with 16533 nodes and 10082 elements. The meshed model is shown in Fig. 6.

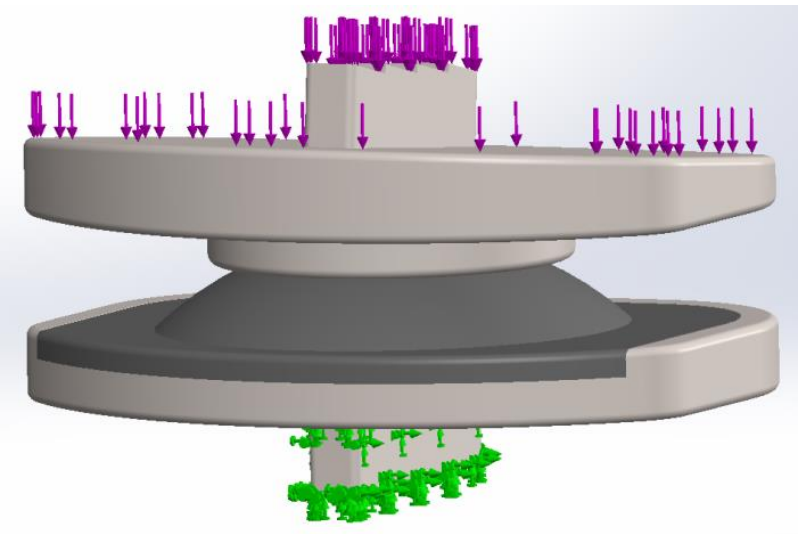

Fig. 5. Constraints and loads acting on the model.

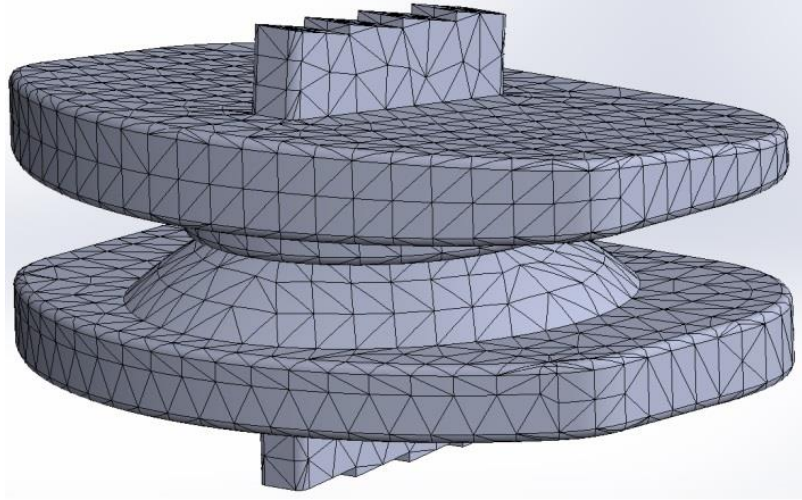

Fig. 6. Triangle mesh generated for the simulation.

\section{Results}

The FEM analyses resulted in obtaining the maps of stress distribution in the artificial vertebral disc, as shown in Figs 7-9. The maximal values of von Mises stress for each element depending on the load and structural material of both pads are listed in Table 2 .

It can be observed that in each material configuration the maximum stresses acting on each element of the prosthesis are almost twice higher in the sitting position than when the patient is recumbent.

In general, the results demonstrate that despite a considerable difference between the mechanical properties of titanium and cobalt alloys, the stresses acting on the prosthesis under given loads have similar values in both cases. The greatest difference in stresses of approximately $2 \%$ can be observed when the prosthetic insert is pressed by the upper pad. Hence, in this case, it seems that titanium alloy characterised by a suitable weight-to-strength ratio and good biological performance [9] is more suitable for the prosthesis than cobalt alloy (Table 1).

However, not only mechanical properties must be taken into account in biomaterials selection, factors such as microstructure, corrosion resistance and wear properties are crucial, too $[12,13]$. This paper offers preliminary results of a study intended to optimise the proposed prosthesis design in compliance with the requirements of modern bioengineering. To this end, ex vivo testing is often employed [6]. However, ex vivo tests must be preceded by FEM simulations.

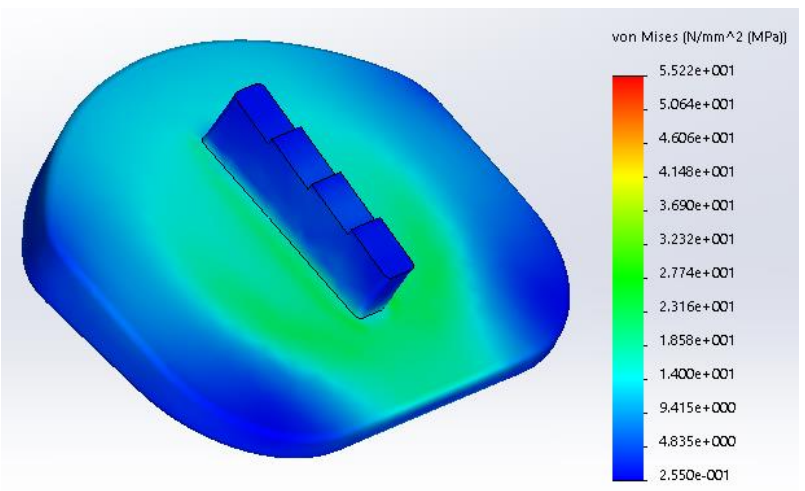

Fig. 7. Stress distribution on the surface of the upper pad. 


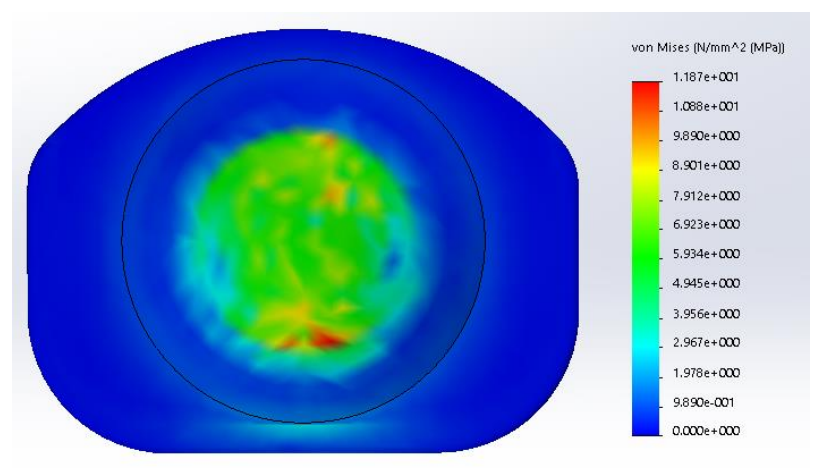

Fig. 8. Stress distribution on the spherical surface of the insert.

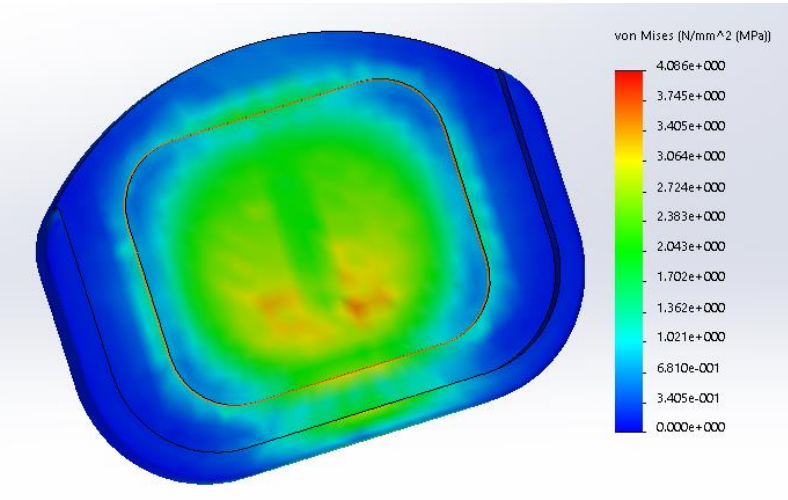

Fig. 9. Stress distribution on the inside of the bottom pad.

Table 2. Maximum stresses acting on prosthesis elements for two material configurations.

\begin{tabular}{|l|c|c|c|c|}
\hline \multicolumn{1}{|c|}{ Element } & Material & $\mathbf{7 5 \% B W}$ & $\mathbf{1 0 0} \% \mathbf{B W}$ & $\mathbf{1 4 0} \% \mathbf{B W}$ \\
\hline \multicolumn{5}{|c|}{ Material Configuration I } \\
\hline Upper pad & Ti-6Al-4V & $41.41 \mathrm{MPa}$ & $55.22 \mathrm{MPa}$ & $77.30 \mathrm{MPa}$ \\
\hline Bottom pad & Ti-6Al-4V & $30.64 \mathrm{MPa}$ & $40.86 \mathrm{MPa}$ & $57.20 \mathrm{MPa}$ \\
\hline Insert & polyethylene & $8.91 \mathrm{MPa}$ & $11.87 \mathrm{MPa}$ & $16.62 \mathrm{MPa}$ \\
\hline \multicolumn{5}{|c|}{ Material Configuration II } \\
\hline Upper pad & Co-Cr-Mo & $41.43 \mathrm{MPa}$ & $55.24 \mathrm{MPa}$ & $77.33 \mathrm{MPa}$ \\
\hline Bottom pad & Co-Cr-Mo & $31.22 \mathrm{MPa}$ & $41.63 \mathrm{MPa}$ & $58.28 \mathrm{MPa}$ \\
\hline Insert & polyethylene & $9.09 \mathrm{MPa}$ & $12.13 \mathrm{MPa}$ & $16.98 \mathrm{MPa}$ \\
\hline
\end{tabular}

In the work [8], the authors conducted a structural analysis of the knee joint endoprosthesis, finding that the weakest element of the model was a polyethylene liner. Therefore, in the present study, a polyethylene disc is used to prevent its damage under the action of stresses.

With the use of titanium alloy, the maximum stresses slightly decrease compared to those observed for the cobalt alloy configuration (Table 2). This is due to mechanical properties of the investigated metal alloys. It is obvious that both Young's module and Poisson's ratio have impact on the FEM results. Moreover, the determined stress values are lower than the nominal strength of the tested materials, therefore the polyethylene insert disc is prevented from damage.
Based on the FEM results, it is possible to claim that the prosthesis design proposed in this paper can withstand loads generated during daily activities, as the maximum stresses acting on the prosthesis elements are significantly under the yield point of each tested material, and the displacements are marginal. However, in order to optimise the proposed design, it is crucial to perform further simulations using different materials like porous titanium and titanium-nickel (shape memory) alloys or implants with modified surface properties [1,3,9-11, 13].

\section{Conclusions}

The objective of this paper was to determine the effect of using cobalt and titanium-based alloys as implant materials for lumbar vertebrae with a polyethylene intervertebral disc on stress distribution. The FEM (finite element method) analysis was conducted for three standard loads reflecting three patient's postures: recumbent, standing and sitting.

The model of an artificial intervertebral disc was designed with the dimensions corresponding to the CT (micro-computed tomography) scans of the patient's spine.

The FEM results demonstrate that the prosthesis proposed in this paper can withstand loads generated during daily activities, as the maximum stresses acting on the elements are significantly under the yield point of each tested material, and the displacements are marginal.

It has been found that in both investigated material configurations, the maximum stresses acting on each element of the prosthesis are almost twice higher in the sitting posture than in the recumbent position.

The FEM simulations of stress distribution have confirmed that both material configurations yield lower values than the nominal strength of the tested materials, which prevents the polyethylene insert disc from damage.

To optimise the prosthesis design, it is crucial that further simulations be performed for different materials and loads.

\section{References}

1. Y.-H. Lee, C.-J. Chung, C.-W. Wang, Y.-T. Peng, C.-H. Chang, C.-H. Chen, Y.-N. Chen, C.-T. Li, Comput. Biol. Med. 71, 35-45 (2016)

2. Z. Gümrükçü, Y. T. Korkmaz, F. M. Korkmaz, Comput. Biol. Med. 86, 47-54 (2017)

3. L. Zach, L. Kunčická, P. Růžička, R. Kocich, Comput. Biol. Med. 54, 53-60 (2014)

4. M. M. Shirazi, O. Abouali, H. Emdad, M. Nabavizadeh, H. Mirhadi, G. Ahmadi, Comput. Biol. Med. 89, 1-17 (2017)

5. R. Karpiński, Ł. Jaworski, J. Zubrzycki, Adv. Sci. Technol. Res. J. 10, 240-246 (2016)

6. J. P. Caffrey, E. Cory, V. W. Wong, K. Masuda, A. C. Chen, J. P. Hunt, T. M. Ganey, R. L. Sah, J. Biomech. 49, 4090-4097 (2016)

7. S. M. Moon, J. H. Yoder, A. C. Wright, L. J. Smith, E. J. Vresilovic, D. M. Elliott, Eur. Spine J. Off. Publ. Eur. Spine Soc. Eur. Spinal Deform. 
Soc. Eur. Sect. Cerv. Spine Res. Soc. 22, 18201828 (2013)

8. J. Zubrzycki, R. Karpiński, B. Górniak, Appl. Comput. Sci. 12 (2016) (available at http://yadda.icm.edu.pl/yadda/element/bwmeta1.el ement.baztech-69507fc1-0eca-4b84-b42a0c1edb67506c)

9. R. A. Gittens, R. Olivares-Navarrete, Z. Schwartz, B. D. Boyan, Acta Biomater. 10, 3363-3371 (2014)

10. A. Dudek, L. Adamczyk, Opt. Appl. 43 (2013) (available at http://yadda.icm.edu.pl/baztech/element/bwmeta1. element.baztech-6bff853a-6c74-46c0-bd04$81008281 \mathrm{c} 5 \mathrm{f} 6$ )

11. S. Sobieszczyk, P. G. Wydawnictwo, Rozwój bioaktywnych implantów porowatych na osnowie stopów tytanu (Wydawnictwo Politechniki Gdańskiej, 2013)

12. M. Walczak, Wplyw wybranych zabiegów technologicznych na trwałość użytkowa uktadów metal-ceramika stosowanych $w$ protetyce stomatologicznej (Politechnika Lubelska, Lublin, Poland, 2014; http://bc.pollub.pl/dlibra/docmetadata?id=8653)
13. S. Taksali, J. N. Grauer, A. R. Vaccaro, Spine J. Off. J. North Am. Spine Soc. 4, 231S-238S (2004)

14. F. H. Netter, Atlas of Human Anatomy (Elsevier Health Sciences, 2010)

15. K. Lipscomb, N. Sarigul-Klijn, E. O. Klineberg, in press, doi:10.1115/IMECE2016-66384

16. R. Będziński, Biomechanika inżynierska: zagadnienia wybrane (Oficyna Wydawnicza Politechniki Wrocławskiej, 1997)

17. Classification of Joints, (available at http://oerpub.github.io/epubjs-demobook/content/m46383.xhtml\#fig-ch09 $01 \quad 02$ )

18. M. A. Adams, P. Dolan, J. Biomech. 38, 1972$1983(2005)$

19. J. P. G. Urban, S. Roberts, Arthritis Res. Ther. 5, 120-130 (2003)

20. K. Luoma, H. Riihimäki, R. Luukkonen, R. Raininko, E. Viikari-Juntura, A. Lamminen, Spine. 25, 487-492 (2000)

21. F. Paulsen, J. Waschke, Sobotta Atlas of Human Anatomy, Vol. 3, 15th ed., English/Latin: Head, Neck and Neuroanatomy (Elsevier,Urban\&FischerVerlag, 2013)

22. Ł. Jaworski, R. Karpiński, J. Technol. Exploit. Mech. Eng. 3, 8-12 (2017) 